\title{
O processo de apropriação das tecnologias digitais móveis: uma experiência na formação continuada do professor de matemática
}

\author{
Maria Elisabette Brisola Brito Prado* \\ Fátima Aparecida da Silva Dias** \\ Willian Rocha Padilha***
}

\section{Resumo}

Este artigo tem por objetivo compreender como um grupo de professores de matemática de uma escola pública pensa e se apropria das tecnologias digitais móveis (TDM), mais especificamente do tablet, durante o processo de formação continuada. A pesquisa de natureza qualitativa envolveu a participação de seis professores que atuam no ensino fundamental da rede pública. A análise dos dados enfatizou quatro momentos: o primeiro contato para saber o que pensam os professores sobre o uso pedagógico das TDM, a oficina com o uso das TDM, a prática com os alunos e a reflexão sobre a prática vivenciada. Os resultados mostraram que o processo de apropriação tecnológica é particular, situado e se dá de forma contínua. Portanto, é necessário propiciar a formação do professor, tendo como foco a reconstrução do conhecimento profissional na perspectiva do TPACK.

Palavras-chave: cultura digital; conhecimento profissional; reconstrução da prática.

* Programa de Pós Graduação em Educação Matemática - Universidade Anhanguera de São Paulo - UNIAN

** Programa de Pós Graduação em Metodologias do Ensino de Linguagens e suas Tecnologias - UNOPAR

*** Universidade Anhanguera de São Paulo - UNIAN 


\section{The process of digital mobile technologies appropriation: an experience in the continuous training of the math teacher}

\section{Abstract}

This article aims to understand how a group of math teachers from a public school thinks about and appropriates mobile digital technologies (MDT), more specifically the tablet during the process of continuous training. The research of a qualitative nature involved the participation of six teachers who work in the public elementary school. The analysis of the datas emphasized four points; the first contact to know what the teachers think about the pedagogical use of MDT, the Workshop with the use of MDT, the practice with the students and the reflection on their experience. The results showed that the process of technological appropriation is particular, situated and occurs continuously. Therefore, it is necessary to provide the teacher with training that focuses on the reconstruction of professional knowledge from the perspective of TPACK.

Keywords: digital culture; professional knowledge; reconstruction of pratice.

\section{El proceso de apropiación de las tecnologías digitales móviles: una experiencia en la formación continuada del profesor de matemáticas}

\section{Resumen}

Este artículo tiene por objetivo comprender cómo un grupo de profesores de matemáticas de una escuela pública piensa y si apropia de las tecnologías digitales móviles (TDM), más específicamente del tablet durante el proceso de formación continuada. La investigación cualitativa con la participación de seis profesores que actúan en la Enseñanza Fundamental de la red pública. El análisis de los datos enfatizó cuatro momentos, el primer contacto para saber lo que piensan los profesores sobre el uso pedagógico de las TDM, el Taller con el uso de las TDM, la práctica con los alumnos y la reflexión sobre la práctica vivenciada. Los resultados mostraron que el proceso de apropiación tecnológica es particular, situado y ocurre de forma continua. Por lo tanto, es necesario propiciar la formación del profesor teniendo como foco la reconstrucción del conocimiento profesional en la 
perspectiva del TPACK.

Palabras clave: cultura digital; conocimiento profesional; reconstrucción de la práctica.

\section{Introdução}

$\mathrm{O}$ avanço das tecnologias digitais da informação e comunicação (TDIC) tem instigado pesquisadores de diferentes áreas do conhecimento a compreender suas possibilidades em relação aos processos de ensino e de aprendizagem. A presença das tecnologias digitais pode influenciar a forma das pessoas se relacionarem e de aprenderem, apesar do seu uso pedagógico, no contexto da escola, ainda ser restrito. Embora existam professores que reconhecem que essa geração de estudantes necessita atribuir novos sentidos e significados aos conteúdos curriculares, por meio de outras linguagens e de diferentes representações do conhecimento, utilizando as tecnologias digitais, eles também alegam que não é uma tarefa fácil de ser feita no contexto da escola.

A dificuldade apontada pelos professores advém de diversos fatores. Um deles, por exemplo, refere-se ao fato de o professor ter que aprender a lidar com recursos tecnológicos e a reconstruir a própria prática docente, aquela que foi construída e consolidada no seu cotidiano escolar muitas vezes sem o uso das TDIC. Nessa situação, surgem inseguranças, indagações, dúvidas; ou seja, o professor sai da "zona de conforto", como enfatizam Borba e Penteado (2010), gerando para alguns a negação e, para outros, o desafio em aprender a usar as TDIC na prática pedagógica.

No entanto, esse desafio torna-se cada vez mais complexo com a presença das tecnologias digitais móveis (laptop, tablet, celular) nas mãos dos alunos em sala de aula. Essa mais recente configuração da sala de aula caracteriza um novo paradigma de ensino e de aprendizagem, que evidencia a necessidade e a urgência da educação atentar-se para as demandas desse cenário representado pela cultura digital.

Historicamente, as tecnologias digitais móveis (TDM) chegaram nas escolas brasileiras em 2007, com a implantação de um 
projeto piloto nacional do Ministério da Educação denominado Projeto UCA (Um Computador por Aluno). Este projeto foi desenvolvido em 300 escolas urbanas e rurais, sendo 10 de cada uma das 27 unidades federativas do país e em todas as escolas de seis pequenos municípios. Posteriormente, este projeto foi expandido em parceria com várias Secretarias da Educação de Estados e de Municípios, ampliando assim o uso das TDM em várias escolas da rede pública do país.

O Projeto UCA deu origem às novas pesquisas, considerando principalmente as caraterísticas da mobilidade e da conectividade. As autoras Almeida e Prado (2009), que participaram desde o início da criação do projeto e acompanharam várias experiências em escolas, constataram em seus estudos que o computador (laptop) nas mãos dos alunos requer uma nova dinâmica pedagógica em sala de aula e gera outros desafios que levam a repensar o currículo no âmbito do sistema educativo. A pesquisa de Mendes (2008) constatou que os professores do ensino fundamental de diversas disciplinas, atuantes em uma escola da cidade de Palmas, do estado de Tocantins, sentiram a necessidade de fazer mudanças no espaço físico da sala de aula, de ampliar o tempo da aula e a forma de conduzi-la. Em decorrência dessa necessidade, o planejamento da aula foi revisto e passou a ser mais dinâmico, exigindo dos professores um olhar mais atento, para manter o foco nos conteúdos das disciplinas sem deixar de contemplar os questionamentos e as descobertas emergentes da interação dos alunos com o laptop em suas mãos.

Para compreender o processo de inserção do laptop nas aulas de um grupo de seis professores que ensinam matemática no ensino fundamental em uma escola municipal localizada no interior do estado de São Paulo, a pesquisa de Eivazian (2012) constatou que cinco professores desenvolveram atividades com o uso do laptop envolvendo, especialmente, criação de desenhos e jogos educacionais. Neste grupo, apenas um professor adotou a metodologia de projetos, propiciando aos alunos vivenciarem uma maneira mais ativa de aprender. No processo de desenvolver o projeto temático 
"Consumo de Água", de caráter interdisciplinar, foram utilizados diversos recursos do laptop de forma integrada aos conteúdos de várias disciplinas e com os materiais didáticos convencionais disponíveis na escola.

Além das experiências com o laptop educacional na prática escolar, chegou nas escolas outro dispositivo móvel (o tablet), também por iniciativa do governo federal. Esse dispositivo móvel fez parte do projeto Educação na Cultura Digital do Ministério da Educação, lançado em 2012, que teve como ponto de partida a preparação dos educadores (professores e gestores) das escolas públicas. Assim, esse novo artefato presente no contexto da escola impulsionou novos estudos e pesquisas relacionadas ao uso pedagógico do tablet e à formação de educadores.

Os estudos de Bairral (2013) enfatizaram que o tablet trouxe um novo modo de interação do usuário com o objeto representado na tela por meio do toque - touchscreen. Os diferentes e simultâneos tipos de toques na tela oferecem ao usuário mais dinamismo e liberdade de manipulação com o objeto. Sob esse enfoque, o autor desenvolveu um estudo no contexto do ensino de matemática com alunos do ensino médio, utilizando o software Geometric Constructer. A análise deste estudo mostrou que a atividade desenvolvida com este software no tablet favoreceu o desenvolvimento do raciocínio geométrico e permitiu constatar que a interação do estudante com o touchscreen "[...] poderá trazer novos insights cognitivos para a educação matemática com esse tipo de tecnologia digital” (BAIRRAL, 2013, p. 16).

Portanto, considerando a realidade da evolução das TDM e a sua forte presença no cotidiano das pessoas, principalmente das crianças e jovens, fica evidente a necessidade de ampliar as investigações sobre as potencialidades do seu uso pedagógico, tendo como foco promover aos professores e estudantes novas formas de ensinar e aprender.

Nesse sentido, o professor tem um papel fundamental em criar situações de aprendizagem significativas para os alunos. Para 
isto, o professor precisa atribuir o sentido pedagógico ao uso das tecnologias digitais pelos alunos, pois, como salienta Valente (2011, p. 31), que se reporta a Alan Kay, “[...] as ideias não estão no laptop [TDM], mas na cabeça das pessoas. São elas e não a tecnologia que criará melhores condições para uma educação coerente com as necessidades da era digital e da mobilidade".

Diante dessa situação fica evidente a necessidade da formação continuada do professor para que ele possa apropriar-se pedagogicamente dos recursos das TDM e integrá-los no cotidiano da prática escolar. No entanto, essa tarefa é complexa, pois é necessário considerar que o professor, durante a sua vida como estudante e profissional, vivenciou práticas baseadas em um paradigma de ensino e de aprendizagem muito diferente do atual. Isso implica, muitas vezes, na revisão de concepções e na (re)construção do conhecimento profissional docente voltado para a era digital.

\section{Conhecimento profissional docente e apropriação tecnológica}

Os estudos mais recentes, tais como os de Lobo da Costa e Prado (2015), Rocha (2015), entre outros, voltados para a área de formação de professores com o uso das tecnologias digitais, têm mostrado a importância de as ações formativas considerarem a base do conhecimento profissional apresentada por Mishra e Koehler (2006) como um modelo teórico denominado de TPACK (Technological Pedagogical and Content Knowledge). Esses autores tomaram como ponto de partida a teoria de Shulman (1986), que introduziu o conceito do conhecimento pedagógico do conteúdo, constituído pela intersecção dos conhecimentos pedagógicos e do conteúdo, caracterizando dessa forma um novo conhecimento exclusivo do profissional professor. A partir desse constructo teórico de Shulman, os pesquisadores Mishra e Koehler acrescentaram o conhecimento tecnológico. Assim, a intersecção desses três conhecimentos (conteúdo, pedagógico e tecnológico) deu origem ao conhecimento pedagógico do conteúdo (CPC), ao conhecimento tecnológico 
do conteúdo (CTC) e ao conhecimento tecnológico e pedagógico (CTP). Por sua vez, a intersecção desses três tipos de conhecimentos - CPC, CTC e CTP - resultou no TPACK.

No entanto, para que o professor possa reconstruir o conhecimento na perspectiva do TPACK, de tal forma que possa integrar as tecnologias digitais ao currículo, é preciso compreender, inicialmente, como se dá o seu processo de apropriação tecnológica no contexto da escola. Esse processo não é simples; muitas vezes, demanda de o professor revisitar concepções pedagógicas, aprofundar conceitos e apropriar-se dos recursos tecnológicos presentes no contexto da escola.

Em se tratando da apropriação tecnológica para uso educacional, os estudos apontados por Sandholtz, Ringstaff e Dwyer (1997), Almeida e Valente (2011), Borges (2009), Lobo da Costa e Prado (2015), entre outros pesquisadores, constataram que a apropriação ocorre em um processo gradativo, constituído por diferentes fases. Tais fases vão desde a apropriação operacional e técnica dos recursos tecnológicos que caracteriza a adoção das tecnologias, passando por fases intermediárias de diversos tipos de adaptação, que envolve uso parcial das tecnologias até chegar nas fases da inovação e da integração.

Daí a importância de compreender o processo de apropriação tecnológica para que a formação continuada do professor, segundo Zeichner (1993), possa enfatizar ações que privilegiam o aprender-fazendo e refletindo sobre a prática pedagógica com o uso das tecnologias digitais de modo a propiciar a reconstrução da base do conhecimento profissional representado pelo TPACK.

\section{Desenvolvimento da pesquisa}

Este artigo tem por objetivo compreender como um grupo de professores de matemática de uma escola pública pensa e se apropria das tecnologias digitais móveis, mais especificamente do tablet, durante o processo de formação continuada.

A metodologia utilizada nesta pesquisa, de natureza qualitativa, desenvolveu-se com base nos princípios apontados por Bogdan 
e Biklen (1994), que consideram o ambiente natural como fonte direta dos dados. A pesquisa envolveu a descrição e interpretação dos dados coletados diretamente da interação dos pesquisadores com um grupo de seis professores de matemática que atuam em uma escola da rede pública. Para preservar o direito ao sigilo de suas identidades, os professores participantes foram denominados por AR, FN, HB, LG, RO.

Os instrumentos utilizados na coleta de dados foram: questionários, entrevistas semiestruturadas, protocolos das atividades desenvolvidas pelos professores e registros dos encontros gravados em vídeo, áudio e diário de campo.

A coleta dos dados foi realizada na própria escola durante a oficina, que ocorreu em oito encontros presenciais. Os pesquisadores atuaram, também, como formadores na oficina, visando preparar os professores para a utilização dos recursos do tablet, de uma forma contextualizada aos conteúdos matemáticos, voltados para a função polinomial do $1^{\circ}$ grau e com recurso ao software Grapher.

Após a oficina, foram feitas observações sobre uma situação da prática de uma das professoras participantes, que se propôs a desenvolver uma aula extracurricular envolvendo seis alunos, utilizando o tablet e o Grapher em atividades de matemática. Ao término dessa prática, foi realizado um encontro com a referida professora, para que pudesse assistir e analisar o vídeo sobre a sua experiência vivenciada com os alunos usando as TDM.

\section{Descrição e análise dos dados}

A análise dos dados apresenta-se organizada em quatro momentos, enfatizando: o que pensam os professores sobre o uso das TDM, aprendendo a utilizar as TDM, praticando o uso das TDM com alunos e refletindo sobre a prática com uso das TDM.

\section{$\mathrm{O}$ que pensam os professores sobre o uso das TDM}

No primeiro contato com os professores participantes da pesquisa, ficou evidente em suas falas que o grupo considera im- 
portante fazer uso das TDM para tornar a aula mais dinâmica e atrativa, visando, com isso, despertar o interesse dos alunos, que são da geração digital, no processo de aprendizagem.

Os dados também evidenciaram que metade do grupo faz uso pessoal do tablet frequentemente para leitura (livros e notícias) e entretenimento (redes sociais, jogos), o que mostra que alguns professores do grupo já têm algum tipo de familiaridade com as TDM. Outra metade do grupo faz uso do computador desktop de forma mais esporádica para digitação e acesso à internet (e-mail, sites).

Um fato que chamou atenção foi que, dos seis professores do grupo, cinco já tinham feito curso de informática e conheciam vários softwares específicos de matemática, mas nenhum deles utiliza esses recursos na sua prática com os alunos. Os professores deixaram explícito que nos cursos de informática que participaram, puderam conhecer e explorar alguns softwares, contudo, o foco dado no curso era apenas técnico. Alguns professores reafirmaram que, mesmo tendo feito o curso, não tinham conhecimento suficiente para trabalhar com os alunos usando as tecnologias digitais.

No entanto, todos os professores do grupo foram unânimes em reconhecer que existem muitas barreiras que impedem e dificultam o uso das tecnologias na escola, tais como: a falta de acesso à internet, tempo restrito da aula, indisciplina dos alunos, falta de investimento e de infraestrutura, bem como de incentivo e apoio da gestão escolar.

Os professores alegaram que precisa haver uma mudança no sistema de ensino, em relação à quantidade de alunos por sala, qualidade e manutenção dos equipamentos tecnológicos e formação dos professores para desenvolver o conteúdo matemático usando os recursos disponíveis nos tablets.

É importante que os professores reconheçam que esses aspectos de diferentes instâncias externas às suas individualidades interferem na prática do professor. Entendemos que esta atitude sinaliza que alguns professores estão mais focados numa fase do processo de apropriação tecnológica, que Prado e Lobo da Costa 
(2015) denominaram de fase periférica, ou seja, aquela que geralmente antecede a adoção da tecnologia no seu dia a dia profissional.

No grupo, apenas dois professores explicitaram que fazem o uso das tecnologias no contexto escolar. O professor RO usa a tecnologia para preparar suas aulas. Por exemplo, utiliza um software para gerar gráficos e depois insere a imagem do gráfico no texto dos enunciados das tarefas digitadas no editor de texto, produzindo dessa maneira um documento mais apresentável para os alunos. Porém, a resolução das tarefas pelos alunos é feita usando apenas lápis, compasso, régua, ou seja, os materiais concretos disponíveis. Esta situação mostra a fase de adoção do processo de apropriação, pois o professor se apropriou da tecnologia para uso próprio, mas não para o uso pedagógico.

A professora FN criou um blog para disponibilizar informações relacionadas à disciplina, como, por exemplo, lista de exercícios e sugestões de vídeos disponíveis na internet. A professora comentou que encontrou uma maneira diferente e mais próxima da linguagem dos alunos usando o blog como complemento da aula. Essa situação, embora tenha um caráter moderno e atual de comunicação com o aluno, usando as TDM, retrata a fase intermediária, denominada de adaptação do processo de apropriação. A professora FN fez uma adaptação da aula tradicional trazendo as tecnologias digitais como um complemento inovador de comunicação com o aluno.

\section{Aprendendo a utilizar as TDM}

A oficina foi desenvolvida sempre atenta ao diálogo com os professores participantes, para que pudessem explicitar suas dúvidas, preocupações e descobertas acerca das potencialidades e restrições relacionadas com o uso das TDM. Os professores, além de se manifestarem verbalmente no coletivo do grupo, alguns elaboraram registros destacando suas observações sobre a experiência de explorar os recursos do software Grapher e do tablet no contexto de função polinomial do $1^{\circ}$ grau, conforme ilustra os registros a seguir:

Em todos os exercícios, o uso do dispositivo móvel é bem interessante, pois a resposta das análises gráficas é bem mais rápida 
e a visualização se torna bem mais esclarecedora do que o gráfico construído manualmente, isso porque você pode trocar os valores e de pronto visualizar um novo gráfico. Isso facilita o entendimento do aluno, para os aspectos que queremos que o mesmo observe. (professor $\mathrm{HB}$ ).

É bem mais fácil demonstrar para o aluno, pois geralmente ele é visual e num toque você pode demonstrar o mesmo gráfico com valores diferentes, além de ser a realidade do aluno, ele consegue perceber mais rapidamente no tablet e consegue fazer análise desses gráficos e comparações das funções. (professora AM).

O grupo de professores enfatizou a importância da agilidade e rapidez que o uso do tablet pode proporcionar nas aulas de matemática como forma de ampliar, por meio do zoom, as coordenadas do gráfico e visualizar com mais precisão a função. No momento de discussão coletiva no grupo, todos os professores do grupo ressaltaram a importância do papel do professor. O grupo argumentou que não adianta apenas colocar a tecnologia nas mãos dos alunos. O professor precisa garantir que o aluno vai aprender o conteúdo. De fato, essa preocupação do grupo é importante e isto implica em rever o papel do professor para atuar no contexto da escola com a presença das TDM.

Analisando a trajetória do grupo na oficina, foi possível perceber a fase de adaptação do processo de apropriação, no momento em que os professores exploravam o tablet nas atividades de funções, ou seja, nas atividades que fazem parte do seu cotidiano profissional. Constatamos que o grupo, mesmo experienciando um novo modo de lidar com os conteúdos matemáticos, reforçava o argumento de que o uso das TDM com os alunos só deveria ocorrer depois de o professor ter dado a aula. Ou seja, o grupo enfatizava que, primeiramente, o professor deveria expor o conteúdo em sala de aula usando lousa e giz, como habitualmente faz, sem a presença das tecnologias digitais, para depois fazer o uso das mesmas. Desta forma, ficou bastante claro, durante a oficina, que o grupo aceita 
utilizar as TDM, mas como um complemento da aula. Esta visão retrata uma justaposição e não a integração das tecnologias ao currículo, na perspectiva de Almeida e Valente (2011). Isto nos mostra que o processo de apropriação na prática do professor não acontece de imediato. O conhecimento de como ensinar, consolidado e arraigado ao longo do tempo, é que dá segurança ao professor de que está exercendo o seu compromisso profissional.

\section{Praticando o uso da TDM com alunos}

Após o término da oficina, a professora AM, que já tinha manifestado interesse em experienciar uma situação prática de uso das tecnologias digitais com alunos, desenvolveu uma atividade envolvendo seis dos seus alunos do $9^{\circ}$ ano do ensino fundamental, em horário extraclasse. Para realizar esta experiência, com a intenção de explorar os recursos do software Grapher e do tablet, no contexto de função polinomial do $1^{\circ}$ grau, AM elaborou um planejamento de duas aulas extraclasse de 50 minutos cada para atingir seus objetivos.

Para desenvolver esta experiência, a configuração da sala de aula, organizada pela professora AM, seguiu praticamente o mesmo modelo usado na oficina. Os seis alunos ficaram sentados numa mesa redonda, formando dois grupos, sendo que cada grupo recebeu um tablet com o software Grapher já instalado. O fato de a professora ter reproduzido a mesma organização de sala de aula, vivenciada durante os encontros na oficina, mostrou que a forma de aprender, trocando ideias, compartilhando descobertas e dialogando com os colegas e o pesquisador/formador foi significativa para ela. Consequentemente, esta vivência da professora permitiulhe construir uma nova referência de ensino usando as TDM.

Assim, a professora AM preparou uma lista de tarefas sobre função, para os alunos resolverem com o uso do tablet e do software Grapher. Entretanto, no dia anterior à aula extraclasse, a professora, na sala de aula regular, explicou os conceitos envolvidos nas atividades de função, usando a lousa e o giz, como era habitual na sua prática docente. Desta maneira, a professora esperava que, durante 
a aula extra, os alunos utilizassem as TDM para visualizar os gráficos da função e confirmar aquilo que tinham aprendido na sala de aula regular do dia anterior.

Logo no início da aula extraclasse, a professora explicou para os alunos o funcionamento do tablet e dos recursos do software Grapher, para auxiliar na visualização e análise dos gráficos. Os alunos ouviram as orientações da professora enquanto manipulavam com muita tranquilidade e curiosidade a tela touchscreen do tablet, descobrindo os diferentes tipos de input e output. A atitude dos alunos surpreendeu a professora em relação à naturalidade com que interagiam com o tablet.

Uma situação, em que era necessário fazer alguns cálculos para resolver a atividade, os alunos espontaneamente utilizaram a calculadora do celular e, em seguida, deram continuidade à resolução da tarefa no tablet, demonstrando autonomia inclusive para mudar as cores das funções, a cor da grade da tela do software, sem que a professora tivesse mostrado essas possibilidades. Os alunos identificaram facilmente que as funções apresentadas eram crescentes, decrescentes ou constantes e, quando um dos alunos não conseguiu uma visualização adequada, um colega mostrou com um pequeno movimento dos dedos (polegar e indicador), que poderia ajeitar os eixos e visualizar as funções na tela do tablet.

Num determinado momento, os alunos expressaram dúvidas sobre o conteúdo e a professora imediatamente procurou lembrá -los de que já havia explicado aquele assunto em sala de aula, no dia anterior. Mas os alunos demonstraram não ter nenhuma lembrança do que tinha sido ensinado; estavam abertos e atentos para aprender naquele momento em que vivenciavam uma situação que fazia sentido para eles. Segundo Papert (1985), é no momento em que o aluno se envolve com a própria aprendizagem que amplia a qualidade das interações do aprendiz com o objeto, e esse é um dos princípios do construcionismo que permite ao aprendiz vivenciar, simultaneamente, o hands on (mão na massa) e o head in (mente envolvida), impulsionado pelo uso das tecnologias (VALENTE, 2002). 
Finalizado o momento praticando o uso das TDM com alunos, foi proposta pelo formador/pesquisador uma nova ação, tanto de caráter formativo como de pesquisa, com a intenção de propiciar à professora AM vivenciar um momento da reflexão sobre sua prática juntamente com os demais participantes do grupo, no sentido salientado por Zeichner (1993).

\section{Refletindo sobre a prática com uso das TDM}

Passados alguns dias da experiência prática com alunos, foi realizado um encontro com o grupo de professores para apresentar o vídeo da aula extraclasse desenvolvida pela professora AM, de modo que ela pudesse revisitar sua prática e analisá-la juntamente com os demais professores do grupo. O que chamou mais atenção do grupo de professores ao assistir o vídeo foi a postura dos alunos, conforme ilustra os registros dos relatos a seguir:

Eu não imaginava que seria tão fácil para os alunos... nunca tinha visto com tanta iniciativa... eu nem precisei explicar como deveriam fazer a tarefa, eles já resolviam tudo e quando precisava de ajuda o colega estava do lado atento querendo ensinar também (professor HB).

Pareciam outros alunos.... a conversa entre eles era só em relação à atividade (professora AR).

Achei fantástica a utilização do tablet para ensinar função do $1^{\circ}$ grau. Os alunos ficaram muito interessados e participaram ativamente da aula a todo o momento (professor LG).

Nesse momento, a professora AM fez o seguinte relato no grupo:

Logo após esta experiência, na aula de matemática regular, uma aluna que participou da aula extra me perguntou se daria para baixar o Grapher no celular e eu não soube responder, mas achava que sim. Na aula seguinte, eu estava continuando com o conteúdo, aí pedi para os alunos fazerem alguns gráficos, dadas as funções que tinha colocado na lousa, e aquela menina, que havia perguntado na aula anterior se o Grapher poderia ser baixado no celular, ela estava fazendo os gráficos diretamente no celular com o software. Ela baixou no celular e fez tudo sozinha... 
A discussão e análise dos professores focaram a atitude dos alunos em relação à autonomia para lidar com a tecnologia e o envolvimento com a atividade. Possivelmente, pelo fato de os alunos perceberem que podem aprender de uma forma diferente daquela em que já não encontram mais sentido, ou seja, aquela aula em que precisam ficar sentados, calados, uns atrás dos outros, apenas ouvindo e olhando para uma lousa cheia de informações sobre as quais não conseguem estabelecer relações e atribuir significados.

Os professores comentaram que, para mudar a prática, é muito difícil, principalmente na realidade da escola, mas que entendiam que os alunos são de uma geração que precisa aprender de outra forma. Sobre a forma de ensinar de maneira diferente, o grupo não tem essa clareza, mas tem a consciência da necessidade da mudança da prática.

Ter essa compreensão é fundamental para a continuidade da trajetória da formação continuada do professor. É importante compreender que não basta colocar a tecnologia na escola e nas mãos dos alunos. É preciso que o professor esteja atento e preparado para reconstruir e recriar a sua prática. É o professor que tem a intencionalidade pedagógica, que orienta, acompanha e faz as intervenções no processo de aprendizagem dos alunos. Como ressaltam Almeida e Valente (2011), a tecnologia por si só não garante que o aluno aprenda os conteúdos curriculares; é necessário que o professor crie situações desafiadoras e dê oportunidade para que o aluno desenvolva sua autonomia intelectual, saiba buscar informações, estabelecer relações, compartilhar questionamentos, dúvidas e colaborar com o outro.

Provavelmente, a oportunidade que o grupo teve de refletir conjuntamente sobre uma situação prática contribuiu para a tomada de consciência de que a presença das TDM na escola desvela a necessidade de repensar o ensino e a aprendizagem, bem como o papel do professor e da educação voltada para as características da sociedade atual. 


\section{Considerações finais}

Sintetizando os momentos representativos da coleta de dados, podemos constatar, em relação ao processo de apropriação tecnológica, que o grupo de professores expressou a coexistência das várias fases de apropriação: a periférica, adoção, adaptação e inovação. A fase de adaptação ficou evidenciada devido à própria condição da estrutura escolar, que torna mais viável para o professor utilizar as TDM pontualmente (como complemento, aula extraclasse) e manter, ao mesmo tempo, a prática habitual desenvolvida no seu cotidiano de sala de aula.

A pesquisa mostrou que o processo de apropriação tecnológica é particular, situado e se dá de forma contínua. Portanto, é necessário propiciar a formação do professor, tendo como foco a reconstrução do conhecimento profissional na perspectiva do TPACK. No entanto, para que ocorra a integração das TDM ao currículo é preciso também rever a dimensão global que abrange a estrutura e a gestão escolar. Caso isto não ocorra, as possibilidades de inovação continuarão acontecendo no âmbito mais restrito e pontual sem contemplar a necessidade urgente de preparar os estudantes para serem os futuros cidadãos da cultura digital.

\section{Referências}

ALMEIDA, M. E. B.; VALENTE, J. A. Tecnologias e currículo: trajetórias convergentes ou divergentes? São Paulo: Paulus, 2011.

ALMEIDA, M. E. B.; PRADO, M. E. B. B. Formação de Educadores para o uso dos computadores portáteis: indicadores de mudança na prática e no currículo. Trabalho apresentado na VI Conferência Internacional de Tecnologias de Informação e Comunicação na Educação, Braga, Portugal, 2009.

BAIRRAL, M. A. Do clique ao touchscreen: novas formas de interação e de aprendizado matemático. Trabalho apresentado na $36^{\mathrm{a}}$ Reunião Nacional da ANPED, Goiânia, 2013.

BOGDAN, R.; BIKLEN, S. Investigação Qualitativa em Educação. Uma introdução à teoria e aos métodos. Tradução de Maria João Alvarez, Sara Bahia dos Santos e Telmo Mourinho Baptista. Porto: Porto Editora, 1994. 
BORBA, M. de C.; PENTEADO, M. G. Informática e Educação Matemática. 4. ed. Belo Horizonte: Autêntica, 2010.

BORGES, M. A. F. Apropriação das tecnologias de informação e comunicação pelos gestores educacionais. 2009. 321 f. Tese (Doutorado em Educação: Currículo) - Pontifícia Universidade Católica de São Paulo, São Paulo, 2009.

EIVAZIAN, A. M. B. O Computador Móvel e a Prática de Professores que Ensinam Matemática em uma Escola do Projeto UCA. 2012. 158 f. Dissertação (Mestrado em Educação Matemática) - Universidade Bandeirante de São Paulo, São Paulo, 2012.

LOBO DA COSTA, N. M.; PRADO, M. E. B. B. Integração das Tecnologias Digitais ao Ensino de Matemática: desafio constante no cotidiano escolar do professor. Revista Perspectiva da Educação Matemática, Universidade Federal de Mato Grosso do Sul, v. 8, n. 16, p. 121-139, 2015.

MENDES, M. Introdução do Laptop Educacional em Sala de Aula: Indícios de Mudanças na Organização e Gestão da Aula. 2008. 79 f. Dissertação (Mestrado em Educação: Currículo) - Pontifícia Universidade Católica de São Paulo, São Paulo, 2008.

MISHRA, P.; KOEHLER, M. Technological Pedagogical Content Knowledge: A framework for teacher knowledge. Teachers College Record, v. 108, n. 6, p. 1017-1054, 2006.

PAPERT, S. M. Logo: Computadores e Educação. São Paulo: Brasiliense, 1985.

PRADO, M. E. B. B.; LOBO DA COSTA, M. N. Educational Laptop Computers Integrated into Mathematics Classrooms. In: GELLERT, U.; GIMÉNEZ RODRIGUEZ, J.; HAHN, C.; KAFOUSSI, S. (Ed.). Educational Paths to Mathematics: A C.I.E.A.E.M Sourcebook. New York: Springer, 2015. p. 351-365.

ROCHA, A. K. O. A programação de computadores como meio para integrar diferentes conhecimentos: uma experiência com professores de Matemática. 2015. 236 f. Tese (Doutorado em Educação Matemática) - Universidade Anhanguera de São Paulo, São Paulo, 2015.

SANDHOLTZ, J. H.; RINGSTAFF, C.; DWYER, D. C. Ensinando com Tecnologia: criando salas de aula centradas no aluno. Porto Alegre: Artes Médicas, 1997.

SHULMAN, L. Those Who Understand: Knowledge Growth in Teaching. Educational Researcher, v. 15, n. 2, p. 4-14, 1986. 
VALENTE, J. A. Um laptop para cada aluno: promessas e resultados. In: ALMEIDA, M. E. B.; PRADO, M. E. B. B. (Org.). O computador portátil na escola: mudanças e desafios nos processos de aprendizagem. São Paulo: Avercamp, 2011. p. 20-33.

VALENTE, J. A. A espiral da aprendizagem e as tecnologias da informação e comunicação: repensando conceitos. In: JOLY, M. C. R. A. (Ed.). A tecnologia no ensino: implicações para a aprendizagem. São Paulo: Casa do Psicólogo, 2002. p. 15-37.

ZEICHNER, K. M. O professor como prático reflexivo. In: A formação reflexiva dos professores: idéias e práticas. Lisboa: Educa, 1993. p. 13-28.

Submetido em: 8-5-2018

Aceito em: 22-5-2018 